Revista do CESP, Belo Horizonte, v.36, n.56, p. 79-91, 2016

\title{
Mulheres à margem na tradição literária
}

\section{Outsiders Women in Literary Tradition}

\author{
Viviane Cunha \\ Universidade Federal de Minas Gerais, Belo Horizonte, Minas Gerais / Brasil \\ vivileda@terra.com.br
}

Resumo: Retratos de mulheres, as substituídas, suas prerrogativas de fiar e tecer desde tempos imemoriais, com ênfase nas mulheres com deformações nos pés, tendo como corpora as narrativas medievais.

Palavras-chave: personagem feminina, mulher substituída, tecelã e fiandeira, mulheres lendárias.

Abstract: Portraits of women, the replaced ones, their prerogatives to spin and weave from immemorial time, with emphasis on women with deformations in the feet, having as corpora the medieval narratives.

Keywords: female character, substituted woman, weaver and spinner, legendary women.

Recebido em 5 de março de 2017 Aprovado em 2 de abril de 2017

O perfil da mulher de tempos passados é bastante marginal se analisado à luz de detalhes, como as deformações físicas, as eternas atividades do trabalho de fiar e tecer, um trabalho que a acantona sempre numa espécie de gineceu, na Antiguidade Clássica, ou até mesmo numa parte do castelo ou de uma abadia feminina, na Idade Média. Além dessas, há aquela mulher que não é dona de seu destino, cuja vontade e ou desejo nunca contam. Ela pode ser substituída em qualquer instância 
por outra, sem que tenha um prévio conhecimento do que lhe acontecerá, enfim, a sua sorte costuma ser decidida por outrem de seu relacionamento familiar ou não.

O topos da noiva ou da esposa substituída é frequente na literatura e remonta ao texto bíblico. A história de Jacob, a partir do relato da Gênese - capítulos 29 a 32 - apresenta um exemplo dessa temática: Jacob se refugia na casa de Labão, o qual tem duas filhas, Lia e Raquel. Jacob encontra primeiro a caçula, Raquel, perto de um poço nas proximidades de Harran. Ele deseja desposá-la, porém Labão não concorda, até que Lia, a mais velha, se case; e promete dar a Jacob a sua filha, com a condição de que trabalhe para ele durante sete anos. Ao fim de sete anos, Jacob, enganado por Labão desposa Lia, a mais velha. Finalmente, Labão concorda em lhe dar Raquel, desde que Jacob fique mais sete anos a seu serviço.

A literatura universal utiliza frequentemente o topos da noiva ou da recém-casada raptada, arrancada do leito conjugal, ou substituída por outras mulheres na noite de núpcias, tanto na Antiguidade Clássica como na Idade Média, topos que atravessa os séculos seguintes, para não falar senão do espaço europeu.

No século XVI, o poeta português, Luis de Camões, revisitará o texto bíblico ao compor este belo soneto:

Sete anos de pastor Jacó servia

Labão, pai de Raquel, serrana bela;

Mas não servia ao pai, servia a ela,

E a ela só por prêmio pretendia.

Os dias, na esperança de um só dia,

Passava, contentando-se com vê-la;

Porém o pai, usando de cautela,

Em lugar de Raquel lhe deu a Lia.

Vendo o triste pastor que com enganos

Assim lhe era negada a sua pastora,

Como se não a tivera merecida;

Começou a servir outros sete anos,

Dizendo: Mais servira, se não fora,

Para tão longo amor, tão curta a vida.

(Soneto XXIX, Luís de Camões) 
O texto camoniano dialoga explicitamente com o texto bíblico: os nomes das personagens são os mesmos, a substituição de uma filha pela outra: Jacob amava Raquel desde o primeiro momento em que a viu perto de um poço, todavia Labão lhe dá Lia como esposa. O poema de Camões apresenta esse sentimento de continuidade de uma lembrança coletiva do texto bíblico, por definição um texto de domínio comum, no qual se reconhece a fonte através da memória histórica que o registrou para a posteridade. $\mathrm{O}$ amor de Jacob por Raquel é um dos belos exemplos de fidelidade ao sentimento, de devoção ao amor primeiro, que não pôde ser substituído no seu coração, apesar de todos os ventos soprarem contra.

A teoria da literatura dispõe de uma vasta terminologia para definir esse tipo de procedimento. Gérard Genette, por exemplo, fala de hipertextualidade. O hipertexto é um texto derivado de outro texto pré-existente ao fim de uma operação de transformação: transformação simples (transpor a ação do texto A para outra época, tal como o Ulysses de James Joyce); e transformação indireta ou imitação: produção de um novo texto a partir da constituição prévia de um novo modelo genérico: a Eneida, de Virgilio. (GENETTE, 1982, p. 7)

O motivo da mulher substituída é sempre recorrente, mas aqui, trataremos da sua substituição na noite de núpcias, topos que é bastante conhecido na literatura da Idade Média, sobretudo através da lenda de Berta, a esposa de Pepino, o Breve. A epopeia francesa Berte as grans pies é uma obra do século XIII, sendo ela remanejamento de um texto perdido, a qual obteve um sucesso extraordinário, pelo fato de as personagens principais serem ancestrais, na realidade, pais de Carlos Magno, uma das figuras mais famosas da época. Nesse poema, - que é uma obra do poeta e menestrel do Brabant, Adenet le Roi - Berta é filha de Flore, rei da Hungria, e da rainha Brancaflor, a qual foi levada a Paris para se casar com Pepino, o Breve, e se vê substituída por Aliste (filha da velha criada Margiste) no leito do rei, na noite de núpcias, em razão de uma artimanha. Berta foi acusada, pela antiga criada, de ter tentado matar Aliste, a falsa rainha, e foi condenada à morte. Porém, os encarregados de assassinála optaram, no último momento, por abandoná-la na floresta do Mans; mataram um porco, e em seguida apresentaram o coração como prova do crime. Esse topos do abandono de uma mulher nobre na floresta é recorrente na literatura, e a história de Branca de Neve é um bom exemplo, assim como o fato de ter sua vida preservada, que é também o caso de Berta. Trata-se, na realidade, do mesmo locus literário. Recolhida pelo 
guarda florestal Simon e sua esposa Constance, já bastante esgotada, sentindo fome e frio, Berta passará depois, dias aprazíveis, durante nove anos e meio, junto ao casal e suas duas filhas: Ysabel e Aiglente.

Após ter tido um sonho, que ela acreditava ser premonitório, Brancaflor foi a Paris, visitar a filha, a quem ela não via depois de oito anos e meio. No percurso ela encontrou um aldeão que se queixava da crueldade da rainha (que ela supunha ser a sua filha) e se surpreendeu. Quando chegou a Paris, sua surpresa foi maior ainda, pelo fato de não poder ver sua filha, pois Margiste inventou uma grave doença para a falsa rainha, a fim de impedir a visita de sua "mãe". Suspeitosa, Brancaflor acaba por descobrir a trama da impostora, graças aos pés de Aliste. Margiste foi queimada em praça pública, Aliste foi internada na abadia de Montmartre. Berta foi encontrada por Pepino que a restabeleceu como rainha, depois de suas últimas peripécias, devido ao fato de que durante os momentos dramáticos de sua angustiada solidão na floresta ela fez juramento de nunca revelar a sua verdadeira identidade, salvo se essa revelação fosse para proteger a sua virgindade. Após as celebrações pomposas de sua união, o casal real - Pepino e Berta - terão dois filhos: Carlos Magno e sua irmã Gilles, aquela que será a mãe de Rolando, o herói da gesta francesa, Canção de Rolando.

Berte as grans piés é assim "a narrativa de uma traição finalmente punida, na qual a vítima é, depois de duras provas, finalmente restabelecida nos seus direitos". (HENRY, 1982, p. 29, nossa trad.). Esta canção de gesta francesa, redigida por Adenet le Roi, por volta de 1275, a partir de um modelo perdido, é constituída de 3486 versos alexandrinos. Mais de vinte versões circularam na Europa, entre os séculos XIII e XV, em latim, espanhol, italiano, flamengo, alemão, e francês, é claro. Mesmo depois da Idade Média a história de Berta continuou a inspirar os escritores.

Sabe-se muito pouco sobre a vida real de Berta. O filólogo francês, Gaston Paris, nos assegura que a sua história está ligada por acaso ao nome de Pepino, o Breve, o pai de Carlos Magno, e que essa narrativa poderia ser uma combinação erudita. Efetivamente, a história é de origem mítica: algumas vezes Berta é associada à rainha de Sabá, por causa dos seus pés. Na versão italiana da epopeia ela é representada com um pé maior do que o outro. Em outras narrativas, Berta é representada com os pés de ganso, a saber, com os dedos unidos. Na França, é muito conhecida a história da rainha Pédauque, em francês, ou rainha Pedauca, 
em occitano, termo que tem origem no latim: pede(m) 'pé' + auca 'ganso' $=$ "pé de ganso".

A lenda da rainha Pedauca, personagem mítica, tem origem em Toulouse, na época em que esta era a capital do reino visigótico. Ela se caracteriza por possuir um "pé de ganso".

O "pé de ganso" é uma particularidade que a rainha Pedauca partilha com outras personagens históricas, também, mais ou menos míticas, como a rainha de Sabá ou como Bertrade de Laon, a conhecida Berta del grand pé. Há também muitas santas, às vezes de origem real ou da nobreza, personificadas em pastoras ou fiandeiras, marcadas com esse signo, ou que padeciam da lepra - sob forma de milagres, para escaparem dos assédios dos pretendentes - como Santa Isberga, em Artés, Santa Neomaia, no centro da França, Santa Enimia, nas "gargantas" do Tarn, no sul da França. O pé de ganso e a lepra estão efetivamente ligados, pois essa doença provoca danos cutâneos, que se assemelham à pele dos palmípedes, e era a marca dos leprosos na Idade Média, conforme assinala a Encyclopédie de Diderot et d'Alembert. (Fonte: <https://oc.wikipedia. org/wiki/Pedauca $>$ ).

Os primeiros textos que evocam a rainha de Toulouse datam do Renascimento. A Tolosanum Gesti, publicada em 1515, a apresenta como "filha de Marcellus, quinto rei de Toulouse, nomeada Austris". Austris era plena de doçura, de modéstia e de bondade. "Deus não quis que uma criatura tão virtuosa abraçasse o culto pagão, então lhe fez padecer de uma lepra disforme". Seu pai mandou construir para ela, no quarteirão dito la Peyralade, em Toulouse, um magnífico palácio, que tinha uma sala denominada banhos da rainha, a qual recebia água de um aqueduto. (Fonte: $<$ https://fr.wikipedia.org/wiki/Reine_Pédauque $>$ ). Isto leva a pensar na rainha Semiramis, esposa de Nino, o qual, segundo algumas versões, mandou construir os jardins suspensos da Babilônia, que era provido de muitas fontes de água, para que a rainha não sentisse falta de seu "país" de origem. Segundo a lenda, Semiramis era uma espécie de peixe metamorfoseado em pessoa humana, por encantamento.

A rainha Pedauca era também evocada no universo das fiandeiras. Ela possuía uma roca maravilhosa, que não se esgotava jamais, permitindo-lhe fiar sem parar. O grande poeta provençal, Frédéric Mistral, na sua famosa obra Trésor du Félibrige, relembra um juramento à moda de Toulouse "par la quenouille de la reine Pédauque"; e cita outro dito: "du temps que la reine Pédauque filait", ao se referir aos "velhos tempos" 
(em português, temos um equivalente: “do tempo do onça"). Rabelais, ao descrever adversarios de pés grandes dizia: "et estoient largement pattez, comme sont des Oyes, et comme jadis à Tholose les portoit la royne Pedaucque". (Fonte: <https://fr.wikipedia.org/wiki/Reine_Pédauque>).

Na realidade, essa associação de rainhas de tempos passados com a tecelagem tornou-se um clichê literário. Nas suas hagiografias, muitas santas costumam ser representadas como tecelãs ou fiandeiras. A mulher que tece aparece também nas pastorelas; em geral, o trabalho produzido com a mão e a agulha é atributo das pastoras que são personagens desse gênero literário. Enquanto exercem a sua atividade pastoril, cuidando dos seus rebanhos, elas carregam o fuso e a linha, e a figura da pastora com o seu instrumento de fiar aparece tanto nas canções tradicionais francesas como nas canções occitanas. Não se pode deixar de lembrar que a atividade de tecer sempre foi prerrogativa das mulheres, desde os tempos bíblicos.

O conto a Dama Pé de Cabra, texto do século XIII, que faz parte do Livro de Linhagens português, assim como a bela amplificatio que fez Alexandre Herculano, no século XIX, são textos bem conhecidos do repertório da literatura portuguesa. O motivo principal dos dois textos são os pés forcados da Dama, a qual não é nomeada em nenhum momento da narrativa. Ela encontra um nobre na floresta, D. Diogo Lopes, senhor de Biscaya, ele se enamora dela, os dois se casam e terão dois filhos. Nessas duas narrativas, na medieval anônima e na romântica, de Herculano, fica claro que a mulher era o demônio, pois fizera um pacto com o marido de este não se persignar. Quando o pacto é quebrado ela desaparece e o texto prossegue contando sobre a sua descendência. O detalhe importante da narrativa são os pés semelhantes aos de uma cabra, que retratam a sua origem e a sua figura maléfica.

Em um processo de reescritura, há outra narrativa tradicional, em que a mulher é nomeada, e evoca contrariamente aos dois primeiros textos o nome da Virgem. Conta-se que na atual região da Beira Alta, mais concretamente na aldeia histórica de Marialva vivia, há muitos séculos atrás, uma donzela muito formosa. Certo dia, um nobre encantado com a sua beleza e querendo desposá-la encomendou os serviços de um sapateiro, pedindo-lhe que fizesse uns sapatos para a donzela em questão. Como se tratava de uma surpresa o sapateiro teria de arranjar uma maneira de conseguir fazer um molde dos pés da donzela para acertar no tamanho do pé. Um dia, sem que esta percebesse, espalhou 
farinha aos pés da cama da donzela, para que quando ela se levantasse, deixasse a marca na farinha espalhada no chão, e assim foi. O sapateiro percebeu pela forma deixada no chão que a donzela tinha "pés de cabra", mas mesmo assim fez uns sapatos adequados. Quando o nobre entrega o presente à donzela, esta com o desgosto de saber que todos já sabiam do seu defeito, atira-se da torre do castelo. A donzela chamava-se Maria Alva e ainda hoje, mesmo em ruínas podemos ver a torre do castelo. $\mathrm{O}$ topônimo Marialva está ligado a uma história interessante, o qual vale a pena citar integralmente, a partir do texto de Anselmo Sousa (SOUSA, 2012):

No topo de um penedo granítico, em posição dominante sobre a vila e a planície cortada pela antiga estrada romana, encontra-se estrategicamente colocado na região fronteiriça do rio Côa um Verdadeiro complexo medieval, as suas raízes mergulham nas brumas do tempo e no passado histórico de Portugal, ligando-se ao trágico destino dos Távora. Não se pode afirmar com certezas absolutas qual a origem do nome de Marialva, mas crê-se que terá sido assim atribuído por Fernando Magno como tributo à Virgem Maria (Maria Alba) visto o culto Mariano ser uma prática comum durante os séculos XI e XII. Embora carecendo de maiores estudos acredita-se que a primitiva ocupação humana deste sítio remonte a um castro dos Aravaros, uma das várias tribos em que se dividiam os Lusitanos (não confundir com Avaros, povo que só viria a surgir na Era Cristã e que nunca pisou solo português). Após a Invasão romana da Península Ibérica, sob o reinado dos imperadores Adriano e Trajano novas obras terão ampliado a povoação que se constituiu numa cidade, denominada nos primeiros séculos da Era Cristã como Civitas Aravorum. Dominando a antiga estrada romana que ligava Celorico da Beira ao Douro, a urbe espraiava-se das fraldas da elevação à planície circundante, conforme o testemunho de restos de construções e da documentação epigráfica resgatada dos trabalhos da arqueologia no subsolo da Devesa. Fonte: <https://www.flickr.com/ photos/anselmo_sousa/8188318534>. Postado em: nov. 2012. Acesso em: 25 abr. 2017. 
No seu excelente artigo sobre o aleijamento, os aleijados e o pé, na literatura grega antiga, Françoise Yche-Fontanel, recorda que "a primazia do pé, no ser humano, não aparece somente enquanto motivo mítico: pode-se medir a sua importância também no nível da expressão escrita e oral, que o tomam sempre como referente". (YCHE-FONTANEL, 2001, p. 83 , cit. orig. em fr., nossa trad.)

A sindactilia é uma má formação congênita, talvez hereditária, caracterizada pela junção e a fusão mais ou menos completa de dois ou mais dedos dos pés ou das mãos, podendo ocorrer tanto em partes moles (sindactilia cutânea) como nos ossos (denominada sinostose). As uniões consanguíneas entre os nobres eram frequentes, tanto na Antiguidade, como na Idade Média, o que devia facilitar o aparecimento de deformações e taras. Esse detalhe dos pés unidos, como aqueles dos palmípedes, será muito explorado na literatura da Idade Média, sobretudo no que concerne às personagens femininas. Isso parece estar ligado à rainha de Sabá, a quem Salomão teria afirmado ser ela uma das mulheres mais belas do mundo, mas que não podia afirmar o mesmo sobre os seus pés. As rainhas Pedaucas (Pés de Ganso), de diversas origens e significações, estão esculpidas nos portais de várias catedrais da França, entre elas a rainha de Sabá.

Segundo uma das lendas de Santa Neomédia, ela era uma pastora, assediada constantemente por um senhor da vizinhança, e ao fazer preces, para pedir a Deus que conservasse a sua virgindade, ela foi dotada com um pé de ganso. Ao avistá-la, assim disforme, o pretendente deixou-a tranquila.

A rainha de Sabá costuma ser apresentada, nas lendas, como uma mulher letrada, uma vez que ela sustentou muitos debates com Salomão, o qual apaixonou-se por ela justamente pelo fato de ser ela uma "mulher de razão", coisa rara na sua época. A personagem Berta descrita pelo trouvère Adenet le Roi é igualmente considerada como letrada na epopéia: "En son lit en seant prist ses heures a dire, / Car bien estoit letree et bien savoit escrire". (versos 402-403, cf. HENRY, 1982, p. 69) Além de ser uma mulher letrada, que sabia ler bem seus livros de horas, em latim, Berta era uma excelente tecedeira, bordadeira e fiandeira, e fazia trabalhos manuais magníficos, a ponto de despertar a admiração de Constance, a mulher de Simon, e de suas duas filhas. Isso a liga a topoi muito arcaicos da literatura grega. 
Todavia, a figura da tecelã é mais que um topos literário, pois ela é preciosa também para as artes visuais tais como a pintura e a escultura. A estatua da Vênus de Milo é um dos mais antigos símbolos da fiandeira nas artes plásticas. A famosa estatua, que se encontra no Museu do Louvre, é representada como se ela estivesse em vias de fiar. Segundo a arqueóloga americana Elizabeth W. Barber, Vênus se encontra na mesma posição que as mulheres gregas quando preparavam o fio para começar a fiar. (cf. BARBER, 1994)

A figura mítica das tecelãs seduziu tanto os pintores anônimos das igrejas românicas da Idade Média - ver, por exemplo, a imagem de Eva, representada na nave da igreja de Saint-Savin-sur-Gartempe, situada na região do Poitou, na França - como o grande mestre da pintura renascentista Diego Velazquez, no seu quadro Las Hilanderas, exposto no Museu do Prado.

As canções de mulheres de diferentes épocas também encenam as tecelãs ou as fiandeiras no seu trabalho de tecer ou fiar, o que mostra a popularidade dessas personagens em várias formas de arte. A Odisseia apresenta muito bem a produtividade do topos das mulheres no trabalho da fiação ou tecelagem, já que esse topos se torna uma espécie de fio condutor da narrativa. Os textos gregos antigos, assim como os textos medievais, mostram as fiandeiras e as tecedeiras em vários aspectos: as mulheres que tecem sozinhas, como a rainha Penélope, ou agrupadas, numa espécie de gineceu, como se pode observar em certas passagens da Odisseia. Dessa forma, tanto a epopeia clássica como a epopeia medieval popularizaram a figura da tecelã/fiandeira.

A obra de Chrétien de Troyes, Philomena, apresenta o mito de Filomela, a qual tece uma tapeçaria para denunciar o seu estupro pelo cunhado. Este, para fazê-la calar-se sobre o ocorrido corta-lhe a língua e a envia à sua irmã Procné. O grande poeta medieval mostra assim que Filomela é um símbolo da mulher condenada ao silêncio desde épocas muito remotas, já que o texto é uma recriação do mito apresentado por Ovidio.

Apesar de "Berta" ser um nome de várias personagens históricas, é bem possível que esteja ligado a Perchta (ou Berchte) uma deusa germânica, presente nos países alpinos. Seu nome significa "a brilhante" e ela está associada ao solstício de inverno. Ela recompensava aqueles que trabalhavam muito durante o ano. Perchta era igualmente encarregada 
de supervisionar os trabalhos de fiação, particularmente aqueles que se referem ao linho.

A lenda de Berta aparece também na obra La Gran Conquista de Ultramar, uma narrativa medieval castelhana, composta de quatro livros:

I. As origens da Primeira Cruzada;

II. Conquista de Antioquia;

III. Conquista de Jerusalém;

IV. A morte de Balduino e História dos últimos reis de Jerusalém.

La Gran Conquista de Ultramar é uma crônica romanceada da Conquista de Jerusalém (1291-1295), que ocorreu durante a Primeira Cruzada, cuja fonte é uma obra em latim (Historia rerum partibus transmarinis gestarum - 1130 / 1184), de Guilherme de Tiro, a partir de uma versão francesa (Conquête d'Outremer ou Roman d'Eracle). Na narrativa principal intercalam-se textos do Ciclo das Cruzadas, assim como poemas em francês e em provençal, sendo a maior parte em estrofes monorrimas e em versos alexandrinos. Entre as fontes da narrativa principal da crônica encontra-se uma versão da Cançon d'Antioca, em provençal, traduzida ao castelhano, assim como das gestas francesas do ciclo carolíngio: Berta la de los grandes pies e Mainete. Os textos sobre Carlos Magno - Berta la de los grandes pies e Mainete (que narra a juventude do futuro imperador franco) - são simples adaptações em castelhano.

O Libro Segundo de La Gran Conquista de Ultramar apresenta uma versão mais resumida do ciclo da juventude de Carlos Magno, no qual aparecem novamente as três narrativas que os compõem: Flores $y$ Blancaflor, Berta la de los grandes pies e Mainete. A inclusão aí desses temas não se justifica, uma vez que eles estão ligados a um cavaleiro cristão chamado Folquet, cujos ancestrais maltrataram um dos meioirmãos de Carlos Magno, nomeados Manfré e Carlón. Esse texto, também conhecido como Cronica Fragmentaria, apresenta algumas diferenças: Flores y Blancaflor são reis de Almeria, que conquistaram territorios, na Africa e na Espanha. Os "grandes pés" de Berta são substituídos pelos "pies d'oca" (ou seja, pés com os dedos unidos), o que associa Berta a tradições mais arcaicas. Ainda nessa versão, Carlos Magno vence o rei mouro de Saragossa, no "Val de Samorián", perto de Toledo, com a sua 
espada Durendarte. Lembre-se aqui que esse é o nome da espada de Rolando da gesta Canção de Rolando. Sigamos a narrativa:

Quando la ynfante Berta su fija fue de hedat de treze años era tan grande de cuerpo que semejaua de veynte años arriba et otrosi era tan fermosa que era marauilla, asi que a ninguna parte non podian saber de muger que tan bien paresçiese commo ella, e tan escorrecha era que su fermosura ouo a sonar por todos los rreynos. E la fija de su ama tan bien era fermosa e apuesta que semejaua mucho a la ynfante, mas quando se ayuntauan amas en vno paresçia la ynfante mucho mas fermosa que la otra; $e$ auie entre ellas vna diferençia bien señalada ca la ynfante auie los pies e las manos muy fermosos e la fija del ama tenie los dos dedos de medio de los pies ayuntados en vno. E algunas vezes acaesçie, que quando andauan jugando en casa de la rreyna, que algunas de las donzellas dubdauan qual era la ynfante o la fija del ama e parauan les mientes a los pies e conosçien las por aquello, e otras las conosçien por la fermosura que avia la ynfante mas que la otra e avn en la palabra, ca era muy mejor rrazonada e de muy mejor continente. (Fonte: $<$ https://cuestadelzarzal. blogia.com/2012/050401-48.-5.-el-testimonio-de-la-granconquista-de-ultramar.php $>$ )

Berta, com a idade de treze anos, parecia ter vinte, por causa de sua altura. Ela era tão bela, que não havia em nenhuma parte uma jovem igual, e sua beleza era conhecida em todos os reinos. A filha da serva era também bela e se parecia muito com Berta. Mas, quando elas estavam juntas a beleza de Berta superava a da outra. Havia entre elas uma diferença bem evidente, já que Berta tinha os pés e as mãos muito bonitos, ao passo que a filha da serva tinha os dedos centrais dos pés unidos, o que permitia identificálas quando estavam juntas. E mais ainda: Berta sabia falar melhor e era mais culta do que a outra. (tradução nossa sob forma de paráfrase).

Essa narrativa castelhana foi escrita a partir da versão primitiva à qual se juntaram as narrativas lendárias: Flores y Blancaflor, Berta, Mainete. Realça-se aqui a beleza de Berta, comparando-a com aquela que se tornaria, mais tarde, sua rival, com uma inversão das duas personagens: 
Berta não tinha nenhum problema nos pés e é por isso que sua mãe se surpreende quando vai a Paris e encontra no seu lugar a impostora, que tinha os pés mal formados, com os dedos unidos, má formação da qual falamos acima. As diferenças entre as duas narrativas explicar-se-iam por interpolações, pois os copistas do scriptorium de Afonso X, o qual teve continuação no reinado de seu filho Sancho IV, tomaram como modelo a epopeia francesa, num processo de reescritura.

Não se pode deixar de lembrar aqui que a literatura medieval se caracteriza, entre outros elementos, pela hipérbole. No que concerne às mulheres sempre se fazem comparações com os mitos ou com seres metamorfoseados, o que não deixa de ser uma maneira de realçar a beleza, a feiura, enfim, trata-se de um instrumento para "fotografar" as imagens das personagens, tais como são representadas nas artes plásticas. Ao se dizer "pescoço de cisne", como na epopeia francesa Le chevalier au cigne, isso não se referiria à ave real, mas seria uma espécie de metonímia para descrever um "pescoço longo". Poder-se-ia dizer a mesma coisa em relação aos pés: os pés de ganso estariam associados a ancestrais atingidos pela lepra, os quais teriam transmitido vestígios a seus descendentes.

Por outro lado, Berta é também representada com os pés grandes, o que seria compatível com o seu tamanho, e ela se assemelhava mais a uma adolescente do que uma mulher adulta (na epopeia francesa ela tem dezesseis anos), conforme dito acima. A tradição literária ou iconográfica costuma apresentar a mulher como uma figura frágil, delicada, e os pés em harmonia com a sua estatura. E possível que os pés grandes não fossem simplesmente uma má formação genética, mas sim uma característica da etnia à qual Berta pertencia: pessoas de alta estatura das quais os pés grandes seriam atributos. $\mathrm{O}$ modelo que os artistas medievais deviam ter diante de si, no espaço românico, seria o das mulheres de pés médios ou pequenos. Os pés grandes não seriam uma hipérbole para descrever a diferença étnica de Berta em relação às mulheres latinas? E os pés de ganso que lhe atribuíam certas narrativas poderiam também remeter a uma tendência da literatura medieval de utilizar a metamorfose, seja transformando os seres humanos, seja comparando-os aos animais, meio de expressão igualmente visual. Não podemos esquecer que numa época na qual as pessoas são massivamente iletradas, os autores poderiam lançar mão da hipérbole e da metamorfose como meios de expressão adaptados para esse público. 


\section{Referências}

ADENET LE ROI. Berthe as grans pies. Ed. Albert Henry. Genève: Droz, 1982.

BARBER, E. W. Women's Work The First 20,000 Years. Women, Cloth and Society in Early Times. New York; London: W. W. Norton \& Company, 1994.

BERARDINELLI, Cleonice Serôa da Motta. Sonetos de Camões. Edição e notas de. Lisbonne/Paris: Fondation Calouste Gulbenkian; Centre Culturel Portugais; Rio de Janeiro: Fundação Casa de Rui Barbosa, 1980. p. 87.

CAMÕES, Luis Vaz de. Sonetos de Camões. Edição e notas de Cleonice Serôa da Motta Berardinelli. Lisbonne; Paris: Fondation Calouste Gulbenkian; Centre Culturel Portugais; Rio de Janeiro: Fundação Casa de Rui Barbosa, 1980. p. 87.

CATALAN, Diego. La Estoria de España de Alfonso X. Creacion y evolucion. (1990). Disponível em: $<$ https://cuestadelzarzal.blogia. com/2012/050401-48.-5.-el-testimonio-de-la-gran-conquista-deultramar.php $>$. Acesso em: 17 mar. $/ 2017$.

GENETTE, Gérard. Palimpsestes. La littérature au second degré. Paris: Éditions du Seuil, 1982.

HENRY, Albert. Adenet le Roi - Berte As Grans Piés. Edition critique. Genève: Droz, 1982.

YCHE-FONTANEL, Françoise. Les boiteux, la boiterie et le pied dans la littérature grecque ancienne. Kentron, Presses Universitaires de Caen, v. 17, n. 2, p. 65-90, 2001. 